\title{
Investigar en los márgenes de las ciencias sociales
}

\section{Researching in the Theoretical Limits of the Social Sciences}

\author{
Alfonso Torres Carrillo*
}

\section{Resumen}

Este artículo presenta una nueva perspectiva para comprender el reciente proceso de reestructuración del campo de los estudios sociales, en particular la emergencia de prácticas investigativas por fuera y en los bordes de las disciplinas sociales. En América Latina, propuestas como la investigación acción participativa y la sistematización de experiencias ponen en evidencia que desde otros lugares sociales diferentes del mundo académico, como los movimientos sociales, se producen prácticas investigativas. Dichas modalidades de producción de conocimiento no solo subvierten los presupuestos epistemológicos de la ciencia clásica, sino que, dado su carácter liminal, abren la posibilidad para avanzar hacia lo inédito, hacia la construcción instituyente de realidades.

\section{Palabras clave:}

Ciencias sociales, investigación acción participativa, investigación liminal, margen investigativo.

\section{Abstract}

This article deals with a new perspective to understand the recent process for restructuring the research field in the social studies. As one example, the emergent research practices like outside and inside of borders in social disciplines. In Latin America; proposals as the Action Research and its experiences of systematization, are known for represent other realities and for show them into the academic world. Another example can be described in the formation and consolidation of new social movements that take place based on the research practice. These modalities of production of knowledge not only subvert the epistemological presuppositions of the classic science, but also, give their liminal character. They open the possibility to advance toward the construction of new realities.

\section{Key words:}

Social sciences, action research, liminal research, researching limits.

Artículo recibido el 14 de marzo de 2008 y aprobado el 12 de mayo de 2008

* Profesor del Departamento de Ciencias Sociales de la Universidad Pedagógica Nacional. atorresc@multiphone.net.co. 
lado los estrechos vínculos de las ciencias sociales con los poderes dominantes y su subordinación a intereses extracognitivos. Además, se les exige a las

\section{Apertura: algo está cambiando en las ciencias sociales}

La próxima apertura de la Maestría en Estudios Sociales en la Universidad Pedagógica Nacional es ocasión propicia para reflexionar acerca de los alcances y potencialidades de las transformaciones que están dándose en el campo de las ciencias sociales, en particular el surgimiento de prácticas investigativas por fuera de las mismas. En efecto, es un hecho aceptado que, desde hace unas décadas, las ciencias sociales atraviesan por un proceso de crisis y reestructuración. Esta dinámica se expresa en la sospecha frente a sus presupuestos epistemológicos, organizacionales y políticos que las configuraron en el siglo XIX, así como la emergencia de nuevas prácticas investigativas no disciplinares.

En primer lugar, se ha cuestionado la fragilidad de sus supuestos positivistas de universalidad, objetividad, determinismo y monismo metodológico. En efecto, hoy se tiende a reconocer que las ciencias sociales siempre están "localizadas", que el sujeto y la subjetividad están presentes en todos sus procesos, que la indeterminación coexiste con el orden y que no existe una única manera de entender el método científico.

En segundo lugar, se ha puesto en evidencia la arbitrariedad de las fronteras disciplinares dentro de las ciencias sociales y entre estas y las llamadas humanidades (Wallerstein, 1996, 1998 y 2001)); a la vez, se reconoce que los campos más dinámicos de la investigación social tienden a liberarse de las ataduras disciplinares (Dogan y Parhe, 1993). Junto a las disciplinas clásicas coexisten prácticas multidisciplinares e interdisciplinares; la investigación se organiza en torno a problemas, cuyo abordaje exige articular y recrear conceptos, metodologías y técnicas de diversa procedencia (transdisciplinaridad); los investigadores sociales más imaginativos incorporan saberes no disciplinares (literatura, cine y sabidurías ancestrales).

En tercer lugar, se ha cuestionado el supuesto de neutralidad de la actividad científica, se han deve- ciencias sociales un compromiso ético con la resolución de las problemáticas sociales actuales (Gibbons y otros, 1997): construcción de democracia, justicia social, reordenamiento territorial, multiculturalismo e interculturalidad, entre otros. Incluso, algunas prácticas de producción de conocimiento, como los estudios de género, los estudios culturales y estudios poscoloniales se reclaman indisciplinares para marcar su diferenciación con las ciencias sociales clásicas que no visibilizaron las relaciones de dominación patriarcal, política y colonial.

En cuarto lugar, se reconoce que el conocimiento de lo social no es patrimonio exclusivo de las disciplinas sociales. En efecto, estas, al igual que lo habían hecho las ciencias naturales desde el siglo XVII, los científicos sociales se abrogaron el monopolio de la producción de conocimiento verdadero sobre lo social; las demás prácticas culturales que venían dando cuenta de lo social, como la filosofía, el ensayo, la sabiduría popular y la literatura, fueron descalificadas por especulativas, faltas de rigor o ficticias. De este modo se erigió una distinción radical entre conocimiento científico y saber común o vulgar (Bunge, 1976).

Dicho abismo epistemológico se ha puesto en sospecha en la medida en que se reconoce a la ciencia como una construcción histórica moderna, un sistema cultural que se impuso a otros igualmente legítimos, como el saber popular y las artes. Las ciencias sociales, por el hecho de tener el mundo social por objeto y de pretender una representación veraz del mismo, deben competir con otros campos de producción simbólica y, en general, con todos los agentes sociales que buscan imponer su visión de la vida social.

Finalmente, se pone en evidencia que el poder del conocimiento científico no deriva de su naturaleza epistemológica, sino del andamiaje institucional que la sostiene. La investigación social encontró su nicho principal en las universidades, sus facultades, departamentos y centros de investigación. Cada disciplina social se esforzó por afinar sus propias 
teorías y métodos, así como por generar instituciones que dieran legitimidad y estatus de ciencia a su producción investigativa: congresos, seminarios, publicaciones periódicas, profesionalización, especializaciones, etcétera.

Por ello, como lo plantea Gayatri Spivak, "todo saber científico se encuentra, ya de antemano, codificado al interior de un tejido de signos que regulan la producción del sentido, así como la creación de objetos y sujetos de conocimiento. Es, entonces, desde cierta política de la interpretación (materializada en editoriales, universidades, centros de investigación, instancias gubernamentales, etc.) que se producen los efectos de verdad de una teoría" (citada por Castro, 1998: 172). ¿Es posible la generación de conocimiento y de teorías por fuera de dicha institucionalidad científica?

\section{Las transformaciones de la ciencia social latinoamericana}

En América Latina, este proceso de reestructuración de las ciencias sociales ha asumido rasgos particulares, dados su origen relativamente reciente, su subordinación a los países centrales y los intentos de producir un "pensamiento propio". En efecto, su emergencia desde la segunda mitad del siglo XX estuvo directamente asociada al proyecto de modernización desarrollista impulsada por Estados Unidos, por lo cual asumieron un compromiso directo con el modelo colonial y la economía capitalista. Desde la década de los sesenta algunos intelectuales, como Paulo Freire, Orlando Fals Borda y Pablo González Casanova, criticaron este colonialismo intelectual y sentaron las bases para pensar América Latina desde su propia especificidad, sin perder el diálogo con otros procesos mundiales y su vocación emancipadora (Barrueta, 2006).

En efecto, las grandes contribuciones latinoamericanas al pensamiento social contemporáneo (teoría de la dependencia, educación popular, teología y filosofía de la liberación, investigación participativa) han surgido como resultado de una apropiación crítica e imaginativa del legado intelectual occidental en función de un posicionamiento crítico frente a la particularidad histórica de la realidad de nuestros países y desde opciones políticas emancipadoras. En la actualidad, la confluencia entre esta tradición crítica latinoamericana y otras tendencias alternativas, como los estudios poscoloniales, ha posibilitado cuestionar la geopolítica de conocimiento hegemónica y valorar el potencial de otros saberes sobre lo social gestados en otras prácticas intelectuales, como los movimientos sociales y las luchas interculturales.

En la región, no ha sido desde las ciencias sociales como institución, sino desde otras prácticas y espacios sociales como la educación popular, la comunicación alternativa, la justicia comunitaria y las luchas sociales en general, desde donde se han hecho los aportes más originales en la generación de conocimiento sobre la realidad social y donde han surgido metodologías novedosas de investigación social; dentro del interés por recuperar la memoria colectiva, comprender prácticas, contextos y actores sociales o develar ideologías y prácticas dominantes, han surgido propuestas como la investigación temática, la investigación acción participativa y la sistematización de experiencias.

Estas redefiniciones en el modo de concebir y orientar las prácticas investigativas en América Latina han encontrado un ambiente más propicio por fuera o en las fronteras de las instituciones especializadas en ciencias sociales. Es el caso de las organizaciones civiles (ONG) que apoyan y acompañan procesos con movimientos y poblaciones populares, como también en el seno de las propias organizaciones sociales. El caso de Fals Borda es paradigmático: es desde una organización civil vinculada con las luchas y organizaciones campesinas y no desde la universidad donde genera la investigación acción participativa, así desde el mundo académico previo y posterior haya mantenido su compromiso ético y político con las causas populares.

La afirmación anterior no debe entenderse como la negación de que en ámbitos universitarios puedan realizarse proyectos y acciones investigativas alternativos. En efecto, son notables (pero escasas) las iniciativas que buscan articular producción de conocimiento y proyección social con poblaciones y movimientos populares. Ya sea por su interés de 
abordar problemas apremiantes como la migración y el desplazamiento forzado o por el establecimiento de acuerdos con organizaciones y movimientos sociales, como lo hace en Brasil la Universidad de Pernambuco con el Movimiento Sin Tierra, MST.

Estas iniciativas, sensibles a las problemáticas y movimientos sociales, no han sido desarrolladas por los departamentos disciplinares (economía, sociología, historia o antropología), sino por programas de trabajo social, educación, comunicación social y psicología comunitaria, o desde instancias "no académicas", como las áreas de bienestar universitario, extensión y proyección social, cuya labor es casi siempre descalificada por parte de los más academicistas. Este dato no es anecdótico: confirma que no es en la centralidad de las ciencias sociales institucionalizadas, sino en sus afueras, donde existe mayor potencial de generación de conocimiento social transformador.

Dicho potencial alternativo presente en la investigación social que se lleva a cabo en los intersticios e intersecciones de las disciplinas sociales, en las fronteras entre la ciencia social y otros campos de producción de saber sobre lo social, como las artes visuales y la literatura, en las fronteras entre academia y acción colectiva, así como dentro de organizaciones y movimientos sociales, amerita ser analizado a profundidad. En consecuencia, en lo que resta de este artículo realizaré una primera caracterización de dichas prácticas investigativas, y luego un balance de su potencialidad de construcción de realidad social y pensamiento crítico.

\section{Los rasgos de la investigación liminal}

Esta investigación social no canónica generada en los bordes de las ciencias sociales la he denominado investigación desde el margen o liminal (Torres, 2004), pero también puede vincularse con otras denominaciones afines que quieren dar cuenta de su emergente novedad y potencia, como epistemología fronteriza (Mignolo), situaciones límite (Freire), pensamiento de umbral (Zemelman) y nomadismo intelectual (Maffesoli).

Investigar desde el margen, lo hemos entendido como un posicionamiento investigativo que tras- grede los límites de la lógica académica dominante; no es estar por fuera, al margen, sino en el umbral del sistema, en sus fronteras: entre el adentro y el afuera, lo instituido y lo instituente, lo conocido y lo inédito, lo determinado y lo indeterminado. Ello permite evidenciar los límites del sistema y abrir nuevas posibilidades al pensamiento y a la acción. Lo marginal abre nuevas posibilidades para pensar, para imaginar, para construir nueva realidad.

Además, lo marginal, lo liminal, asumido no solo como postura epistémica, sino también como posicionamiento ético y político, permite ver, decir y hacer lo que no es visible, nombrable o factible desde el centro de las instituciones de conocimiento y poder. Así como los “marginales", ponen en evidencia los límites y las arbitrariedades del orden social, la investigación liminal hace visible el agotamiento de las disciplinas sociales para abordar y encauzar ciertas realidades constituyentes.

Más allá de cualquier conceptualización sobre la investigación desde el margen o liminal, es necesario hacer una caracterización de las prácticas investigativas que incluimos bajo tal categoría. Para ello, y basado especialmente en la experiencia colombiana, iré respondiendo a las preguntas básicas sobre: ¿por qué surge este tipo de investigaciones? ¿Quiénes son sus impulsores? ¿Para qué se realizan? ¿De qué temáticas se ocupan? ¿Desde cuáles lugares epistemológicos y perspectivas interpretativas se orientan? ¿Cuáles estrategias y técnicas investigativas se abordan?

Con la precaución de no plantear generalidades explicativas determinantes de la emergencia de estas prácticas investigativas en América Latina, me permito sugerir que han sido múltiples los factores y condiciones que permiten comprenderla ${ }^{1}$. Factores y condiciones que se ubican en un lapso de varias décadas y que a su vez pasan a ser elementos constitutivos de estas mismas dinámicas emergentes.

En primer lugar, la propia historicidad de las sociedades latinoamericanas, singular con respecto

1 Amerita una investigación sistemática la sola caracterización descriptiva de dichos contextos, actores, contenidos, finalidades y resultados de tales prácticas emergentes. 
a las de las sociedades de los países centrales que sirvieron como referente empírico de las ciencias sociales clásicas. En efecto, las teorías y metodologías predominantes en las disciplinas sociales tenían como fuente imaginarios culturales anclados a la cultura moderna occidental (orden, progreso, naturaleza humana) y se habían construido a partir de las modernas sociedades industrializadas. Cuando fueron confrontadas con la realidad latinoamericana desde una actitud crítica, se pusieron en evidencia sus limitaciones para dar cuenta de su especificidad y su carácter ideológico y colonial.

El ejemplo de lo primeros sociólogos colombianos formados en Estados Unidos y Europa es diciente. Tanto Orlando Fals Borda como Camilo Torres habían sido formados dentro de la perspectiva funcionalista y en el uso de técnicas estadísticas de análisis social. Pero al llegar a la convulsionada Colombia no encuentran una sociedad ordenada e torno a unos valores compartidos y unas instituciones funcionales, sino un país convulsionado por la violencia, con unas culturas políticas, relaciones y prácticas sociales difíciles de encajar dentro de las categorías clásicas aprendidas.

En segundo lugar, contrariando el dictamen cientificista de separación del científico de la política, estos investigadores pronto asumieron responsabilidades y compromisos con programas y propuestas de acción social y política. Por eso, a diferencia del grueso de sociólogos posteriores que optaron por no incomodarse frente a este impasse, subordinando la realidad frente a la teoría y al método, estos pioneros intentaron acuñar nuevas categorías y generar nuevas estrategias de acercamiento a la vida social y de producción de datos, involucrando activamente a las poblaciones afectadas por los problemas que se investigaban.

Así mismo, otras condiciones históricas y estructurales peculiares del continente, así como de realidades emergentes, han representado un desafío a la investigación social crítica: condiciones como ser el patio trasero del imperio estadounidense, haber padecido unos procesos acelerados de urbanización, padecer prácticas y culturas políticas como el caudillismo y el clientelismo, sufrir dictaduras militares durante largos periodos, estar sometida al modelo neoliberal y poseer una composición étnica singular con fuerte presencia indígena y afro, pero también problemáticas como la migración y el desplazamiento forzado, las juventudes y las culturas urbanas han demandado nuevas perspectivas de investigación social.

Otro factor, evidenciado en el ejemplo anterior, es que un rasgo de la realidad latinoamericana de la década de los sesenta proyectado hacia el presente es la presencia de luchas sociales que buscan enfrenar las situaciones y condiciones de injusticia, dominación, discriminación y exclusión estructurales en el continente. En efecto, las luchas sindicales, campesinas, de pobladores, de mujeres, poblaciones étnicas, etc., pronto demandaron de los intelectuales de las universidades su compromiso desde lo que se esperaba podían aportar: teorías "científicas" y conocimientos especializados sobre la realidad social acerca de la que se pretende actuar.

Del mismo modo, así como muchos de los intelectuales "comprometidos" aplicaron acríticamente ideologías, teorías y metodologías de las ciencias sociales clásicas reproduciendo la lógica moderna colonial, en algunos casos investigadores individuales o colectivos generaron otras prácticas que cuestionaban y generaban alternativas al modo tradicional de producción de conocimiento. Es el caso de personajes como Paulo Freire, Pablo Casanova, Mario Kaplun, el mencionado Fals Borda, quienes de una manera u otra desarrollaron investigaciones novedosas que permitieron comprender de otras maneras y desde otras miradas los problemas de los que se ocuparon.

En tercer lugar, es innegable la recepción imaginativa de perspectivas críticas provenientes de otras latitudes, no siempre del norte, así como la voluntad de algunos intelectuales latinoamericanos de generar pensamiento propio. En efecto, con la institucionalización de las ciencias sociales también llegaron autores disidentes y teorías críticas. El marxismo en las décadas de los setenta y los ochenta jugó este papel en algunos ámbitos, auque en otros se asumió dogmática y ortodoxamente, cercenando su potencial crítico. 
Luego, la recepción entre algunos académicos de perspectivas como el posestructuralismo, el feminismo, la perspectiva de género, los estudios culturales, los estudios subalternos y poscoloniales, y de autores como Foucault, Deleuze y Guattari han inspirado abordajes originales de luchas y dinámicas culturales emergentes, aunque con estos autores ha predominado la recepción doctrinaria, en muchos casos elitista y conservadora.

En el continente existe una rica tradición de intelectuales que han planteado y asumido la necesidad de un pensamiento propio, que a la vez que buscan enraizarse en la peculiaridad de la condición histórica de la región y dialogan críticamente con otras propuestas, se atreven a adoptar nuevas posiciones, perspectivas y lenguajes. Es el caso de Paulo Freire, Antonio García, Orlando Fals Borda, Camilo Torres Restrepo, Rodolfo Stavehaven, Florestan Fernández, Agustín Cueva, Hugo Zemelman, Aníbal Quijano, Nelly Richards, Beatriz Sarlo y Arturo Alape, para citar algunos.

Estos pensadores y creadores se ubican en lo que algunos autores han llamado perspectivas de borde, y otros, razonamientos de umbral, para referirse a formas de conocimiento social que resultan de búsquedas en espacios diferentes y con modalidades diferentes, posibilitando el ascenso a otras racionalidades culturales; se trata de perspectivas que, además de dar cuenta de la interrelación de diferentes campos de conocimiento, constituyen en sí mismas nuevas lecturas sobre la realidad (Chanquía, 1995).

Para Emma León (1995: 56) estas formas de razonamiento conducen a dos aspectos considerados cruciales:

Por un lado, encontrar nuevas facetas a los contenidos producidos y acumulados en esferas particulares del conocimiento, lo que implica ubicar tales contenidos más allá de los márgenes decantados por las teorías establecidas; por otro lado, y en relación estrecha con lo anterior, operar fuera de estos márgenes les permite enfrentarse con la necesidad de abordar nuevas realidades, y construir conocimientos que respondan a ámbitos de sentido diferentes de los ya definidos.
Finalmente, la emergencia de estas modalidades investigativas también tiene que ver con la existencia de sujetos individuales y colectivos que las agencien. ¿Quiénes son? Por un lado, intelectuales provenientes o aún anclados en la institucionalidad de las ciencias sociales (universidades y centros de investigación), que por sus opciones políticas o temáticas mantienen vínculos orgánicos con realidades extraacadémicas. Citado por Richard (1998: 260), García Canclini plantea al respecto que:

parece que la mayor versatilidad de los estudios culturales latinoamericanos para atravesar fronteras se debe, tanto al carácter precario de nuestros sistemas universitarios, como al hecho de que los investigadores combinan su pertenencia universitaria con el periodismo, con la militancia social o política, o la participación en organismos públicos, todo lo cual posibilita relaciones más móviles entre los campos del saber y el actuar.

Asumir opciones políticas, éticas y epistémicos de disidentes, alternativas o transformación social, plantea al trabajo intelectual la necesidad no solo de enfrentarse a exterioridades prácticas más allá de la academia, sino a cuestionar las propias reglas de juego de la institucionalidad científica. Es lo que plantea Maffesoli (1993: 29) con su metáfora de nomadismo intelectual:

De manera que la empresa que se inicia es libertaria. Hacer escuela es fácil y aburrido; es mucho más fecundo esforzarse por echar una mirada libre, a la vez insolente, ingenua, incluso trivial, en todo caso desagradable, pero que abre brechas y permite fuertes intercambios que los mercaderes y burócratas ni siquiera imaginan. Así pues, insolencia de pensamiento... Al trastornar el orden establecido de las cosas y las personas, el nomadismo se vuelve expresión de un sueño inmemorial que el embrutecimiento de lo instituido, el cinismo económico, la reificación social o el conformismo intelectual no llegan jamás a ocultar totalmente.

Además de estos intelectuales nómadas, la real garantía de la pervivencia de la prácticas investigativas de borde es la existencia de sujetos colectivos para quienes sea necesaria la producción de conoci- 
miento y pensamiento desde y sobre otras realidades emergentes. Me refiero en particular a organizaciones y movimientos sociales, que, desde las exigencias de sus propias luchas y desafíos políticos y sociales requieren caracterizar los contextos y estructuras sociales a las que se enfrentan, la especificidad de los actores y acciones emprendidas, como de las subjetividades y racionalidades que producen.

Estos actores sociales asumen el rol de intelectual orgánico colectivo, el cual busca producir conocimiento, no para profundizar en las teorías o lógicas disciplinares, sino para transformar realidades. Es decir, las finalidades que orientan este tipo de investigaciones son políticas, más que epistémicas. Por tanto, al asumir una perspectiva de construcción de realidades (Zemelman), pone a los investigadores de borde en una posición diferente de la del investigador atrapado en la racionalidad disciplinar y en las lógicas meramente académicas.

El punto de partida de una investigación temática, de una investigación participativa, de una recuperación de memoria colectiva o de una sistematización de experiencias es el tener claridad acerca de las preguntas políticas sobre el porqué, para qué y para quiénes va a tener sentido la investigación a realizar, pregunta muchas veces ausente en los proyectos convencionales. Así mismo, es desde estas preocupaciones frente al contexto que se definen las preguntas y problemáticas de investigación, las categorías orientadoras y la perspectiva interpretativa y las opciones y estrategias metodológicas, y no los parámetros de una disciplina o teoría predeterminados.

Este ensanchamiento de los sujetos y modos de investigar nos lleva a hablar de prácticas investigativas, retomando la categoría de prácticas intelectuales propuesta por Daniel Mato (2005) para poner en sospecha la imagen del intelectual como el académico. Hay prácticas intelectuales no solo en el mundo académico, sino también en los movimientos sociales y en las organizaciones sociales y civiles (ONG).Las prácticas literarias y filosóficas en América Latina fueron, y aún lo son, lugares donde se gestó pensamiento al margen de las disciplinas (Mignolo, 1998: 53).
Otro rasgo caracteristico de la investigación de borde es la manera de construir sus problemáticas de investigación. Al respecto, es interesante constatar que ha venido dándose un tránsito en el orden de las preocupaciones que va de asuntos marcadamente "estructurales" y macrosociales, hacia temáticas emergentes de dimensiones, realidades constituyentes de escalas sociales muchas veces moleculares, más no menos importantes. Así, del énfasis en la dependencia, la dominación imperialista, la dominación ideológica y la particularidad de la estructura de clases que marcó el pensamiento crítico de izquierdas entre los años sesenta y comienzos de los ochenta del siglo pasado, se fue pasando a la pregunta por los nuevos actores y movimientos sociales, las subjetividades, los nuevos vínculos y las sociabilidades, así como la memoria, lo cotidiano y la experiencia presente.

En este tránsito en los énfasis están presentes, sin lugar a dudas, las propias transformaciones de los contextos globales, nacionales y locales), de las relaciones sociales y de los movimientos sociales, como también las permanencias y cambios en los imaginarios y paradigmas que configuran la racionalidad de las ciencias sociales latinoamericanas. Vale la pena destacar que una constante ha sido la atención a poblaciones, vínculos y prácticas sociales a su vez "marginales", como los pobladores urbanos, las mujeres, los jóvenes o los "habitantes de la calle" y sus anónimas prácticas y formas de estar juntos; así, desde los intersticios de las estructuras sociales puede verse lo cotidiano, lo efervescente, lo subterráneo.

$\mathrm{Al}$ respecto, considero pertinente destacar un aporte en el mismo sentido, hecho por uno de los sociólogos poco conocido de la escuela de Chicago a comienzos del siglo XX, quien estudió el mundo de las pandillas:

Probablemente el concepto más importante del estudio es el término intersticial; es decir, que pertenece a espacios situados entre una cosa y otra. En la naturaleza, las materias extrañas tienden a reunirse y apelmazarse en todas las grietas, hendiduras y resquebrajaduras: los intersticios. También hay fisuras y fallas en la estructura 
de la organización social. La pandilla se puede considerar como un elemento intersticial en el marco de la sociedad, y el territorio pandilleresco, como una región intersticial en el trazado de la ciudad (Thrasher, 1963, citado por Ulf Hannerz, 1993: 49).

\section{La potencia de la investigación liminal}

En estas problemáticas emergentes y actores marginales privilegiados por la investigación de borde podemos situar el interés por situaciones liminales, emergentes. El propio Freire acuñó en La pedagogía del oprimido la categoría de situación límite dentro de su propuesta de investigación temática. Las situaciones límite son entendidas como problemas que evidencian los límites del orden social y el potencial humano para superarlas; representan un desafío al pensamiento, al permitir reconocer las determinaciones sociales de su actuar y la capacidad de los hombres para generar otras circunstancias (el inédito viable) para superarlas (Freire, 1970).

La perspectiva liminal también encuentra una potencial fuente de elaboración desde los aportes del antropólogo Victor Turner (1988), quien al estudiar los ritos de paso identificó tres fases: una preliminar, que corresponde al estatus que el neófito a va abandonar; una intermedia, donde se produce la metamorfosis del iniciado, llamada liminal o de margen; y una final, que constituye un último movimiento en el que el pasajero se acomoda a su nuevo lugar en la organización social.

La fase y el personaje liminales implican una situación extraña, indeterminada. Victor Turner llama a esa situación como interestructural. El transeúnte ritual no tiene nada, ni estatuto, ni propiedad, ni signos, ni rango que lo distingan de quienes comparten su situación. Actualmente, esta condición de transeúntes, de monstruos del umbral, la desempeñan personajes como los inmigrantes, los adolescentes, los enamorados, los artistas y los outsider en general (Delgado, 1999: 111). La ambigüedad estructural del adolescente, del inmigrante, del enamorado, del artista o del outsider, su anonadamiento, resultan idóneos para resumir todo lo que la sociedad pueda percibir como ajeno, pero instalado en su propio interior; están, a la vez, adentro y afuera, no son de aquí ni son de allá.

Para Turner (1988), lo liminal pone en evidencia la existencia de dos modos de interacción humana. Uno es el estructural, ordenado, diferenciado, jerarquizado, etc. El otro representa un punto neutro de lo social, es comunidad esencial, sin estructurar, naciente. Al primer modelo, lo llama estructura, al segundo, communitas; ambos están presentes permanentemente. Lo comunitas surge allí donde no hay estructura social; es decir, donde lo que hay es ausencia, carencia o cuando menos grave debilidad de lo orgánico social.

La tensión comunitas-estructura de Turner se parece mucho a lo sugerido por Guattari y Deleuze (1982) con las categorías de arborescencia y rizoma, a la diada institución y estado naciente, propuesta por Alberoni (Reguillo, 1996:29) y a la dupla subjetividad instituida y subjetividad emergente, planteada por Hugo Zemelman $(1997,1998)$. En todos los casos se destaca el reconocimiento de lo subterráneo, del vínculo anónimo no controlado por el poder, la fuerza transformadora de lo invisible y el acontecimiento en la creación de novedades sociales, de vislumbrar, "el inédito viable" (Freire, 1970: 121).

Resulta así sugerente destacar que este tipo de investigación marginal promovida por investigadores transeúntes, desde perspectivas de umbral y referida a problemáticas, fenómenos y poblaciones subalternas o emergentes, en la mayoría de los casos vistos como marginados social o simbólicamente, también asume modos singulares de entender la propia práctica investigativa; en particular, los usos críticos y creativos de la teoría, de las tradiciones metodológicas, de las estrategias y de las técnicas de investigación.

Así como en lo social, los momentos y situaciones liminales evidencian los límites del sistema y posibilitan lo nuevo. Instituyendo nuevos vínculos sociales, las prácticas de conocimiento social hechas desde el borde permiten miradas y abordajes inéditos que desbordan los límites de la ciencia social instituida. Como señalaba antes, el hecho de no estar de antemano subordinadas a la racionalidad disciplinar, permite una mayor flexi- 
bilidad y creatividad en la manera de relacionarse con el conocimiento acumulado sobre lo social (categorías, conceptos, lenguajes) e incorporar otras miradas y voces a la hora de abordar e interpretar sus problemáticas.

De este modo, las prácticas investigativas marginales buscan relacionarse con lo teórico no desde una lógica deductiva o demostrativa, sino como "caja de herramientas". Se acude a enfoques y conceptos provenientes de diferentes disciplinas, los cuales no son asumidos "en bloque", sino que son deconstruidos, desarticulándolos, rearticulados o resignificados en función de la especificidad de los problemas de investigación. En algunos casos, se va más allá y se proponen categorías, metáforas y lenguajes nuevos que amplían los sentidos de comprensión de las realidades estudiadas.

Pese a este esfuerzo por relacionarse crítica y creativamente con los corpus conceptuales existentes, hace falta más audacia en la construcción de alternativas interpretativas críticas y en la reflexión epistemológica que dé cuenta de las nuevas búsquedas. Este vacío puede ir llenándose en la medida en que se conozcan y discutan planteamientos que vienen haciéndose en esta dirección por pensadores como Hugo Zemelman, Gloria Andaluza y las llamadas teorías decoloniales.

Frente a la racionalidad parametral propia de la investigación disciplinar, Zemelman propone asumir un pensamiento categorial (1987), que en lugar de aplicar teorías existentes a unos objetos definidos dentro de los límites de aquellas, posibilite reconstruir la racionalidad con que fueron construidas y permita una apertura de pensamiento a la especificidad de las problemáticas que se estudian, especialmente a las realidades y subjetividades constituyentes (Zemelman, 1998). Para el autor, las teorías son realidad condensada, recortada en un momento dado; son "puntas de iceberg" que permiten reconocer las cristalizaciones del magma social, ocultando su movimiento y densidad (Zemelman, 2002).

"Andalzua muestra la necesidad de una epistemología fronteriza, posaccidental, que permita pensar y construir pensamiento a partir de los intersticios y que pueda aceptar que los inmigrantes, los refugiados, los homosexuales, etcétera, son categorías fuera de la ley desde una epistemología monotípica que normaliza ciertos espacios como espacios de contención y marginación" (Mignolo, 1998: 55). Para esta autora, "el latinoamericanismo debe entenderse como una estrategia reconstructiva de carácter fundamentalmente política: una actividad contradisciplinaria y antirrepresentacional que busca liberar las diferencias" (Castro, 1998: 185).

Finalmente, resultan sugerentes los planteamientos que viene haciendo un grupo de intelectuales latinoamericanos desde hace unos años a partir de la crítica de las herencias culturales coloniales de larga duración enquistadas en la modernidad. En el ámbito investigativo, la colonialidad se expresa como dependencia epistémica frente a los modelos de pensamiento generados por la modernidad occidental. Dicha "colonialidad del saber" es desafiada por los conocimientos otros, presentes en otras racionalidades y en las prácticas de resistencia de las luchas y movimientos sociales y culturales (Nómadas, 2007).

Pese a la escasa reflexión epistemológica sobre sus prácticas, la investigación de borde ha demostrado una gran imaginación creadora en lo referente a las estrategias y operaciones metodológicas. Han tenido como un rasgo central rescatar el lugar central del sujeto y la subjetividad en la investigación social; tanto de los sujetos de conocimiento, generalmente minimizados o invisibilizados por la investigación social clásica, como también de la densidad de los sujetos y subjetividades sociales presentes en las problemáticas de investigación social.

En cuanto al ensanchamiento de los sujetos de investigación, el rol de investigador se extiende a otros actores "no especialistas" a la vez que transforma su carácter. Por un lado, profesionales provenientes de diferentes campos se involucran como investigadores, al igual que actores sociales provenientes de organizaciones y movimientos sociales. Por otro, sean o no asumidas como "participativas", hay una preocupación de relacionarse con la población involucrada en las problemáticas 
de estudio, reconociendo y potenciando su calidad de sujeto. Esta con-fusión entre investigadores e investigados supera la preocupación por la subjetividad, incorporando el principio de reflexividad (Ibáñez, 1998: 13).

La implicación práctica de involucrar no especialistas y la población de base como sujetos es que la participación se convierte en un problema ineludible. Plantea la necesidad de estar atentos a reconocer y valorar cómo está dándose en cada uno de los momentos y en cada una de las decisiones del proceso investigativo (Cendales y Torres, 2007). En consecuencia, el diálogo entre los participantes se convierte en una exigencia que no solo garantiza la confluencia de diferentes saberes, sino la garantía de transformación de relaciones de poder predominantes en la investigación convencional.

Los enfoques y estrategias metodológicas más frecuentes son las llamadas cualitativas ${ }^{2}$ y participativas. Los estudios de caso, la etnografía basada en la observación participante, las historias de vida, el análisis de escenarios y acontecimientos, los talleres pedagógicos, los grupos de discusión y el rescate de la memoria colectiva son recursos metodológicos empleados. En muchos casos, las investigaciones trazan sus propias rutas y recrean o inventan técnicas cuyo rasgo común es posibilitar la expresión, a través de sus diferentes lenguajes, por parte de los actores.

Un rasgo común es que al reivindicar la dimensión sujetiva de la vida social y pretender reconocer los sentidos presentes y emergentes en las experiencias sociales estudiadas, la investigación de borde se abre a lenguajes narrativos, desenmarcándose de la rigidez y frialdad del lenguaje académico. La literatura, el cine, el video, la multimedia, el teatro y la plástica son empleadas como estrategia en la construcción de conocimiento. El relato también es

2 Reconozco que bajo esa denominación se cobijan diversas perspectivas epistemológicas, enfoques, estrategias y técnicas que tendrían en común valorar la dimensión subjetiva de la vida social $y$, por tanto, buscan dar cuenta de los sentidos y experiencias de los sujetos en sus contextos cotidianos retomando su propio punto de vista (Denzin y Lincoln, 1994). En todo caso, tomo distancia con la frecuente identificación de lo cualitativo con la ausencia de técnicas o informaciones cuantitativas. la posibilidad de liberar la experiencia única e irrepetible; es la posibilidad de los sujetos de construir su realidad y de configurar identidades.

\section{Balance: potencialidades y límites de la investigación de borde}

Con el panorama presentado, se ha evidenciado que junto a la investigación rutinaria y de frontera está generándose una investigación de borde, la cual desde las fronteras de las ciencias sociales y las instituciones académicas modernas y otras prácticas sociales constituye una apertura crítica a las inercias y reduccionismos de los modos predominantes de producción de conocimiento. A lo largo del texto, hemos insistido en su potencialidad emancipadora, su capacidad de trasgredir límites, de vislumbrar nuevos horizontes y perspectivas.

Sin embargo, el campo de la investigación social, como todo campo, es arena de conflicto en el que las posiciones están en permanente tensión y movimiento; así como las prácticas investigativas de borde han sabido retomar algunos de los lenguajes y conceptos de las prácticas académicas hegemónicas, también esta puede, y de hecho lo hace, incorporar de aquellas algunas de sus rasgos, despojándolos de cualquier potencial transformador.

En este sentido, ninguno de los rasgos descritos garantiza a perpetuidad su potencial crítico, emancipador o alternativo. En efecto, algunas de las propuestas descritas son atraídas permanentemente por la fuerza del imán de la institucionalidad académica. Así como "los conocimientos expertos, que en manos de la élite sirvieron para consolidar los poderes hegemónicos, funcionaron también como recursos reflexivos con efectos negativos para sus intereses: crearon espacios de trasgresión que fueron aprovechados por los subalternos" (Castro 1998: 195), también la ciencia institucionalizada está presta a retomar técnicas, estrategias y prácticas investigativas otras para subsumirlas a la lógica científica dominante.

Un ejemplo reciente es la rápida institucionalización y absorción desde el poder hegemónico de perspectivas que en su momento funcional fueron "alternativas", como es el caso de los estudios cultu- 
rales en Colombia, que no llegaron por la vía de la escuela de Birmingham, sino por el de los estudios literarios norteamericanos y decepcionados especialmente por intelectuales y espacios académicos con escasos vínculos con procesos de lucha política o social; por ello, muy pronto devinieron en programas de posgrado, eventos académicos y autoridades canónicas.

Por ello, no sobra insistir que lo que le da el carácter de potencialidad a las prácticas investigativas

\section{Bibliografía}

Bunge, Mario. (1976). La ciencia, su filosofía y su método. Bogotá: Comuneros.

Castoriadis, Cornelius. (1997). Ontología de la creación. Bogotá: Ensayo y Error.

Castro, Santiago y Mendieta, Eduardo (coordinadores). (1998). Teorías sin disciplina. Latinoamericanismo, poscolonialidad y globalización en debate. México: USE-Miguel Ángel Porrúa.

Cendales, Lola y Torres, Alfonso. (2007). La sistematización como práctica formativa e investigativa. En Pedagogía y saberes, 26. Bogotá: Universidad Pedagógica Nacional.

Cubides, Humberto et ál. (2007). ¿Uno solo varios mundos? Diferencia, subjetividad y conocimientos en las ciencias sociales contemporáneas. Bogotá: IESCO, Universidad Central.

Delgado, Manuel. (1999). El animal público. Barcelona: Anagrama.

Denzin, Norman y Lincoln, Yvonna. (1994). Handbook of qualitative reseca. California: Sage Publications. Thousand Oaks.

Dogan, Matei y Pahre, Robert. (1993). Las nuevas ciencias sociales. La marginalidad creadora. México: Grijalbo.

Freire, Paulo. (1970). Pedagogía del oprimido. México: Siglo XXI Editores.

Gibbons y otros. (1997). La nueva producción de conocimiento. La dinámica de la ciencia y la investigación en las sociedades contemporáneas. Barcelona: Ediciones Pomares-Corredor. de borde no son sus actores, lugar institucional, perspectivas conceptuales o estrategias metodológicas, sino su intencionalidad y sentido político. Su posicionamiento crítico frente al orden instituido de poder y saber y su capacidad de desplegar energías transformadoras. Estamos pensando en lo que Castoriadis (1997) llama imaginario radical y Zemelman (1998 y 2002), subjetividad constituyente: exigencia de historicidad, voluntad de superación de lo dado y apertura a lo inédito, a lo utópico. \}

Grassi, Valentina. (2007). La investigación en el Centro de Estudios sobre lo Actual y lo Cotidiano. En Convergencia. Revista de Ciencia Sociales, 44. Toluca: UAEM.

Ibáñez, Jesús. (1998). Nuevos avances en investigación social. Barcelona: Proyecto ediciones.

Jiménez, Absalón y Torres, Alfonso. (2004). La práctica investigativa en ciencias sociales. Bogotá: Universidad Pedagógica Nacional.

Maffesoli, Michel. (1993). El conocimiento ordinario. México: Fondo de Cultura Económica Sociología.

Maffesoli, Michel. (2005). México: El nomadismo. Breviarios Fondo de Cultura Económica.

Hannerz, Ulf. (1993). Exploración de la ciudad. Madrid: Fondo de Cultura Económica.

Mato, Daniel. (2005). Estudios y otras prácticas intelectuales en cultura y poder. En: Mato, Daniel (compilador). Cultura, politica y sociedad. Buenos Aires: Flacso.

Reguillo, Rossana. (1996). La construcción simbólica de la ciudad. Guadalajara: Iteso.

Maffesoli, Michel. (2007). Una sociología de lo actual y de lo concreto. La emergencia de nuevos fenómenos de tribalismo. En Revista Anthropos, 215: Barcelona.

Sánchez, Irene y Sosa, Raquel (coordinadoras). (2004). América Latina: los desafíos del pensamiento crítico. México: Universidad Nacional Autónoma de MéxicoSiglo XXI Editores.

Turner, Víctor. (1988). El proceso ritual. Estructura y antiestructura. Madrid: Taurus.

Wallerstein, Inmanuel (coordinador). (1996). Abrir las ciencias sociales. México: Universidad Nacional Autónoma de México-Siglo XXI Editores. 
Wallerstein, Inmanuel. (1998). Impensar las ciencias sociales. México: Universidad Nacional Autónoma de México-Siglo XXI Editores.

Wallerstein, Inmanuel. (2001). Conocer el mundo, saber el mundo. Una ciencia social para el siglo XXI. México: Universidad Nacional Autónoma de México-Siglo XXI Editores.

Zemelman, Hugo. (1987). Uso crítico de la teoría. México: El Colegio de México.

Zemelman, Hugo. (1992). Los horizontes de la razón. Dialéctica y apropiación del presente (2 vols.). Barcelona: Anthropos-El Colegio de México.
Zemelman, Hugo. (1994). Racionalidad y ciencias sociales. En: Suplementos 45, Anthropos, Barcelona.

Zemelman, Hugo. (1998). Sujeto : existencia y potencia. Anthropos. Barcelona.

Zemelman, Hugo. (2002). Necesidad de conciencia. Un modo de construir conocimiento. Anthropos. Barcelona.

Zemelman, Hugo y León, Emma. (1997). Subjetividad: umbrales del pensamiento social. Barcelona: Anthropos. 